\title{
Design and analysis of an external-rotor internal-stator doubly fed induction generator for small wind turbine application by fem
}

\author{
Hacene Mellah, Kamel Eddine Hemsas \\ Dept. Electrical engineering, Setif, Algeria \\ Email adress: \\ has.mel@gmail.com (H. Mellah), hemsas.kamel@gmail.com (K. Eddine Hemsas)
}

\section{To cite this article:}

Hacene Mellah, Kamel Eddine Hemsas. Design and Analysis of an External-Rotor Internal-Stator Doubly Fed Induction Generator for Small Wind Turbine Application by Fem. International Journal of Renewable and Sustainable Energy. Vol. 2, No. 1, 2013 , pp. 1-11. doi: 10.11648/j.ijrse.20130201.11

\begin{abstract}
In this paper, a time stepping 2D and 3D FEM is performed for modeling and analysis external rotor DFIG .The finite element method currently represents the state-of-the-art in the numerical magnetic field computation relating to electrical machines. FEM is a numerical method to solve the partial differential equations (PDE) that expresses the physical quantities of interest, in this case Maxwell's equations. This will result in a more accurate result compared to analytical modeling, which can be regarded as a simplification of the PDE. FEM analysis is used for transient mode, magnetic field calculation, the magnetic flux density and vector potential of machine is obtained. In this model we including, non linear material characteristics, eddy current effect, torque-speed characteristics, ambient temperature effect and magnetic analysis are investigated using MAXWELL program. With this program, the components of the DFIG can be calculated with high accuracy.
\end{abstract}

Keywords: DFIG, Outer Rotor, FEM, Wind Turbines, Renewable Energy

\section{Introduction}

There is now general acceptance that the burning of fossil fuels is having a significant influence on the global climate. Effective mitigation of climate change will require deep reductions in greenhouse gas emissions, with UK estimates of a $60-80 \%$ cut being necessary by 2050 [1], Still purer with the nuclear power, this last leaves behind dangerous wastes for thousands of years and risks contamination of land, air, and water[2]; the catastrophe of Japan is not far. Wind power can contribute to fulfilling several of the national environmental quality objectives decided by Parliament in 1991. Continued expansion of wind power is therefore of strategic importance [3], hence, the energy policy decision states that the objective is to facilitate a change to an ecologically sustainable energy production system [3], as example the Swedish Parliament adopted new energy guidelines in 1997 following the trend of moving towards an ecologically sustainable society. The decision also confirmed that the 1980 and 1991 guidelines still apply, i.e., that the nuclear power production is to be phased out at a slow rate so that the need for electrical can be met without risking employment and welfare. The first nuclear reactor of Barseback was shut down 30th of November 1999. Nuclear power production shall be replaced by improving the efficiency of electricity use, conversion to renewable forms of energy and other environmentally acceptable electricity production technologies [3]. On the individual scale in Denmark Poul la Cour, who was among the first to connect a windmill to a generator [4]. In real wind power market, three types of wind power system for large wind turbines exit. The first type is fixed-speed wind power (SCIG), directly connected to the grid. The second one is a variable speed wind system using a DFIG or SCIG. The third type is also a variable speed wind turbine, PMSG [5]. One can noticed two problems of PMSG used in wind power. First is the inherent cogging torque due to magnet materials naturally attractive force. This kind of torque is bad for operation, especially stopping wind turbine starting and making noise and vibration in regular operation. The other one is the risk of demagnetization because of fault happening and overheating of magnets. This risk is very dangerous and the cost for replacing bad magnets is much higher than the generator itself [5]. 


\section{Advantage of DFIG in WT Systems}

There are several reasons for using variable-speed operation of wind turbines; the advantages are reduced mechanical stress and optimized power capture [7]. Speed variability is possible due to the $\mathrm{AC}-\mathrm{DC}-\mathrm{AC}$ converter in the rotor circuit required to produce rotor voltage at slip frequency. Using a back-to-back converter allows bidirectional power flows and hence operation at both suband super-synchronous speeds. Formulating the control algorithm of the converters in a synchronously rotating frame allows for effective control of the generator speed (or active power) and terminal voltage [6]. Without forgotten the second major advantage of the DFIG, which has made it popular, is that the power electronic equipment only has to handle a fraction $(20-30 \%)$ of the total system power [3] This means that the losses in the power electronic equipment can be reduced in comparison to power electronic equipment that has to handle the total system power as for a direct-driven synchronous generator, apart from the cost saving of using a smaller converter.

\section{Review of Related Research}

The development of modern wind power conversion technology has been going on since 1970s, and the rapid development has been seen from 1990s. Various wind turbine concepts have been developed and different wind generators have been built [7].

In specialized literature several types of the machine was developed; we can find a PMSM with internal rotor [8] or with external rotor [9], even the comparative studies between the two preceding topology was made [10], Also in [11] it presents a study of interior rotor IG by FE, DC machine [12], external rotor SRM [13], in the references [14-15] we find a study of the internal rotor DFIG by FE. Even of the special structure machine like a doubly stator or doubly rotor, this special machine is intended for special applications [16], but the study of external rotor DFIG really can treat by the researchers and does not find a paper in this field.

The average annual growth rate of wind turbine installation is around $30 \%$ during last ten years [18]. At the end of 2006, the global wind electricity generating capacity increased to $74223 \mathrm{MW}$ from $59091 \mathrm{MW}$ in 2005. By the end of 2020, it is expected that this will have increased to well over $1260000 \mathrm{MW}$, which will be sufficient for $12 \%$ of the world's electricity consumption [7-18]. Fig. 1 depicts the total wind power installed capacity for some countries from 1999 to 2010. The countries with the highest total installed capacity are Germany (20 $622 \mathrm{MW}$ ), Spain (11 $615 \mathrm{MW})$, the USA (11 $603 \mathrm{MW})$, India (6270 MW) and Denmark (3136 MW) [7-18].

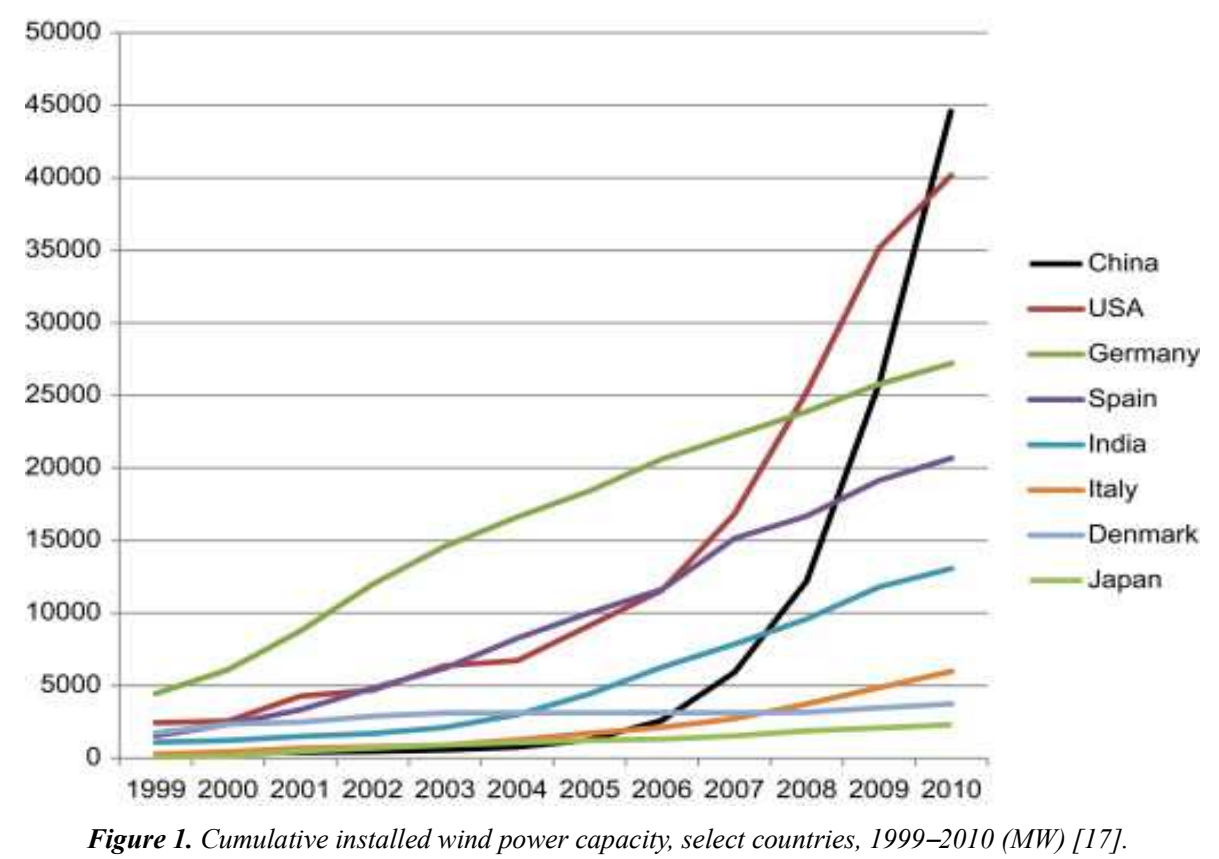

In addition, the Global Wind Energy Council (GWEC) results, Europe continues to lead the market with 48,545 MW of installed capacity at the end of 2006, representing $65 \%$ of the global total installation. The European Wind Energy Association (EWEA) has set a target of satisfying $23 \%$ European electricity needs with wind energy by 2030 . It is clear that the global market for the electrical power produced by wind turbines has been increasing steadily, which directly pushes the wind generation technology into a more competitive area [7-18].

The energy production can be increased by $2-6 \%$ for a variable-speed wind turbine in comparison to a fixed-speed wind turbine, while in it is stated that the increase in energy can be 39\% [3]. The gain in energy generation of the variable-speed wind turbine compared to the most simple fixed-speed wind turbine can vary between 3-28\% 
depending on the site conditions and design parameters. Efficiency calculations of the DFIG system have been presented in several papers [3]. A comparison to other electrical systems for wind turbines are, however, harder to find. One exception presented is in [3], where Datta et al. have made a comparison of the energy capture for various WT systems. The energy capture can be significantly increased by using a DFIG. They state an increased energy capture of a DFIG by over $20 \%$ with respect to a variable-speed system using a cage-bar induction machine and by over $60 \%$ in comparison to a fixed-speed system. One of the reasons for the various results is that the assumptions used vary from investigation to investigation. Factors such as speed control of variable-speed WTs, blade design, what kind of power that should be used as a common basis for comparison, selection of maximum speed of the WT, selected blade profile, missing facts regarding the base assumptions etc, affect the outcome of the investigations. There is thus a need to clarify what kind of energy capture gain there could be when using a DFIG WT, both compared to another variable-speed WT and towards a traditional fixed-speed WT [3].

\section{DFIG Description}

Doubly-fed induction generators (DFIGs) are widely used in wind power systems. A DFIG works as a component of a wind power system, as shown below, where the wind turbine transforms wind energy into mechanical energy, and the DFIG transforms mechanical energy into electrical energy. For a DFIG, both the stator and the rotor are equipped with poly-phase $\mathrm{AC}$ windings. The stator and rotor windings may, or may not, have the same number of phases, but they must have the same number of poles $p$ [15].

A DFIG system can deliver power to the grid through the stator and rotor, while the rotor can also absorb power. This depends on the rotational speed of the generator. If the generator operates above synchronous speed, power will be delivered from the rotor through the converters to the network, and if the generator operates below synchronous speed, then the rotor will absorb power from the network through the converters [1].

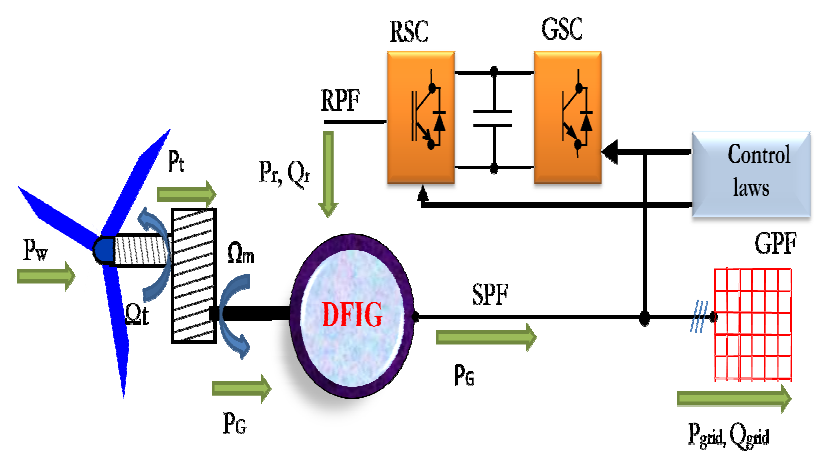

Figure 2. Typical configuration of a DFIG wind turbine.
In order to produce terminal voltages with desired frequency $f$ in the stator winding, the rotor winding must be excited by balanced poly-phase currents with the slip frequency Sf via an AC-DC-AC convert. Slip s is defined as [15]:

$$
s=1-n / n_{0}
$$

Where $\mathrm{n}$ is the rotor speed, and $\mathrm{n} 0$ is the synchronous speed as given below:

$$
n_{0}=60 \mathrm{f} / \mathrm{p}
$$

When the rotor speed is lower than the synchronous speed, the rotor currents have the same phase sequence as the stator currents, and the rotor winding gets power from the converter. However, when the rotor speed is higher than the synchronous speed, the phase sequence of the rotor currents is different from that of the stator currents, and the rotor winding outputs power to the converter [1], [15].

For a given wind turbine, the power coefficient (the ratio of turbine power to the wind power), is a function of the tip speed ratio (the ratio of the blade tip speed to the wind speed). In order to track the maximum power point, the tip speed ratio must keep constant - at its optimal value.

The efficiency is defined as:

$$
\eta=\frac{P_{\text {elec }}}{P_{\text {mech }}} 100 \%
$$

$\mathrm{P}_{\text {ele }}$ : total electrical output power.

$\mathrm{P}_{\text {mech }}$ input mechanical power.

\section{Geometric Dimension and Parameters Design of DFIG}

The operation principle of electric machines is based on the interaction between the magnetic fields and the currents flowing in the windings of the machine.

Rotational Machine Expert (RMxprt) is an interactive software package used for designing and analyzing electrical machines, is a module of Ansoft Maxwell 12.1 [19].The geometries of the motors are shown in Fig 5.

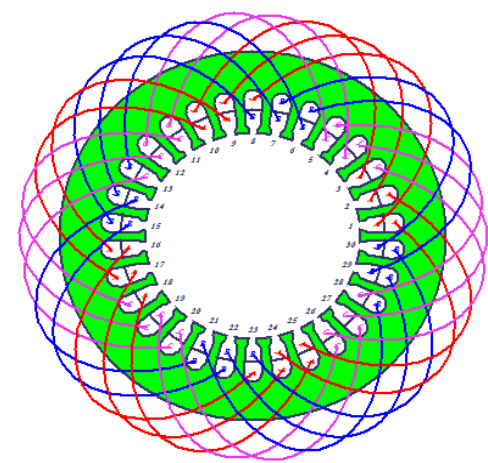

Figure 3. Stator and coil structure of the designed generator. 
Table 1. Stator and rotor slot parameters.

\begin{tabular}{ll}
\hline Stator Slot parameter & Rotor Slots parameter \\
\hline hs0 $(\mathrm{mm}): 2$ & $\mathrm{hr} 0(\mathrm{~mm}): 2$ \\
hs1 $(\mathrm{mm}): 2$ & $\mathrm{hr}(\mathrm{mm}): 2$ \\
hs2 $(\mathrm{mm}): 15$ & $\mathrm{hr} 2(\mathrm{~mm}): 10$ \\
bs0 $(\mathrm{mm}): 2.5$ & $\operatorname{br} 0(\mathrm{~mm}): 2.5$ \\
bs1 $(\mathrm{mm}): 9.19419$ & $\operatorname{br} 1(\mathrm{~mm}): 8.5281$ \\
bs2 $(\mathrm{mm}): 5.24462$ & $\operatorname{br} 2(\mathrm{~mm}): 10.6303$ \\
rs $(\mathrm{mm}): 2$ & $\mathrm{rr}(\mathrm{mm}): 2$ \\
\hline
\end{tabular}

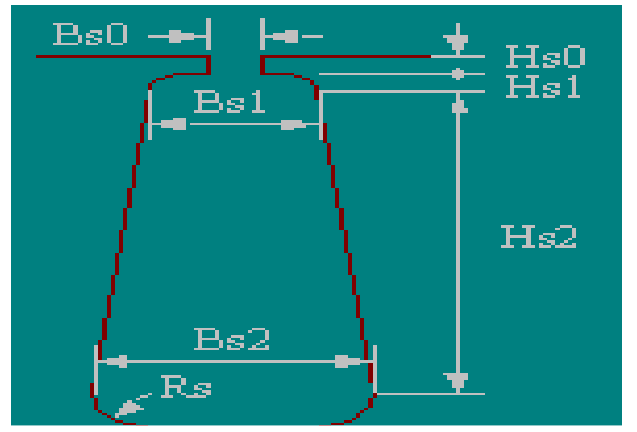

Figure 4. Slot type.

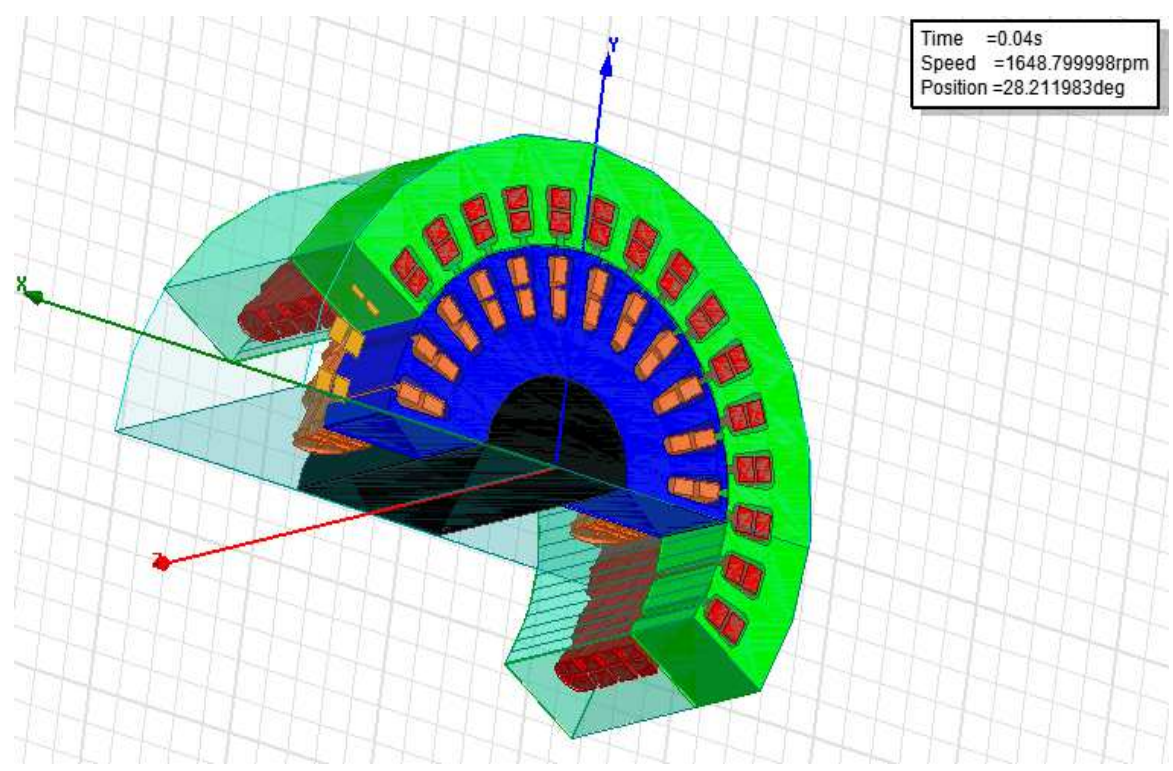

Figure 5. 3D view of the DFIG outer rotor designed.

Table 2. Some rated values, geometric parameters of the designed machines.

\begin{tabular}{ll}
\hline Rated Output Power (kW) & $\mathbf{0 . 5 5}$ \\
\hline Rated Voltage (V) & 220 \\
Given Rated Speed (rpm) & 1500 \\
Number of Poles & 4 \\
Outer Diameter of Stator (mm) & 50 \\
Inner Diameter of Stator (mm) & 24 \\
Number of Stator Slots & 180 \\
Outer Diameter of rotor (mm) & 121 \\
Inner Diameter of Rotor (mm) & 24 \\
Number of Stator Slots & 65 \\
Length of Stator Core (Rotor) (mm) & 0.97 \\
Stacking Factor of Stator Core & 0.97 \\
Stacking Factor of Iron Core & 12 \\
Frictional Loss (W) & 75 \\
Operating Temperature (ÛC) & 24 \\
\hline
\end{tabular}




\section{Simulation Results}

The finite element model is created. First, the geometric outlines are drawn, which is similar to the available mechanical engineering packages. Then, material properties are assigned to the various regions of the model. Next, the current sources and the boundary conditions are applied to the model. Finally, the finite element mesh is created. In the solver part, the finite element solution is conducted [19].

\subsection{Efficiency of DFIG at Variable Environmental Thermal Condition}

The DFIG performance is obtained, by considering a variable ambient temperature, Fig 7 . Show the influences of environmental thermal condition on efficiency, the increase in the ambient temperature, so the DFIG losses increase, thus the efficiency decreases.

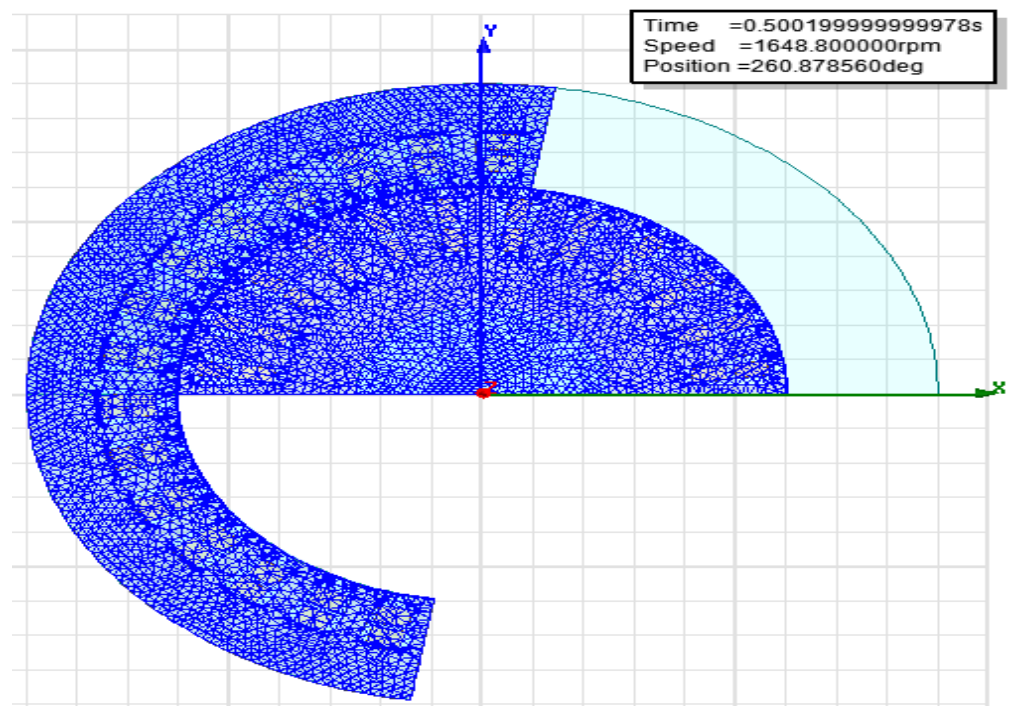

Figure 6. 2D DFIG outer rotor mesh.

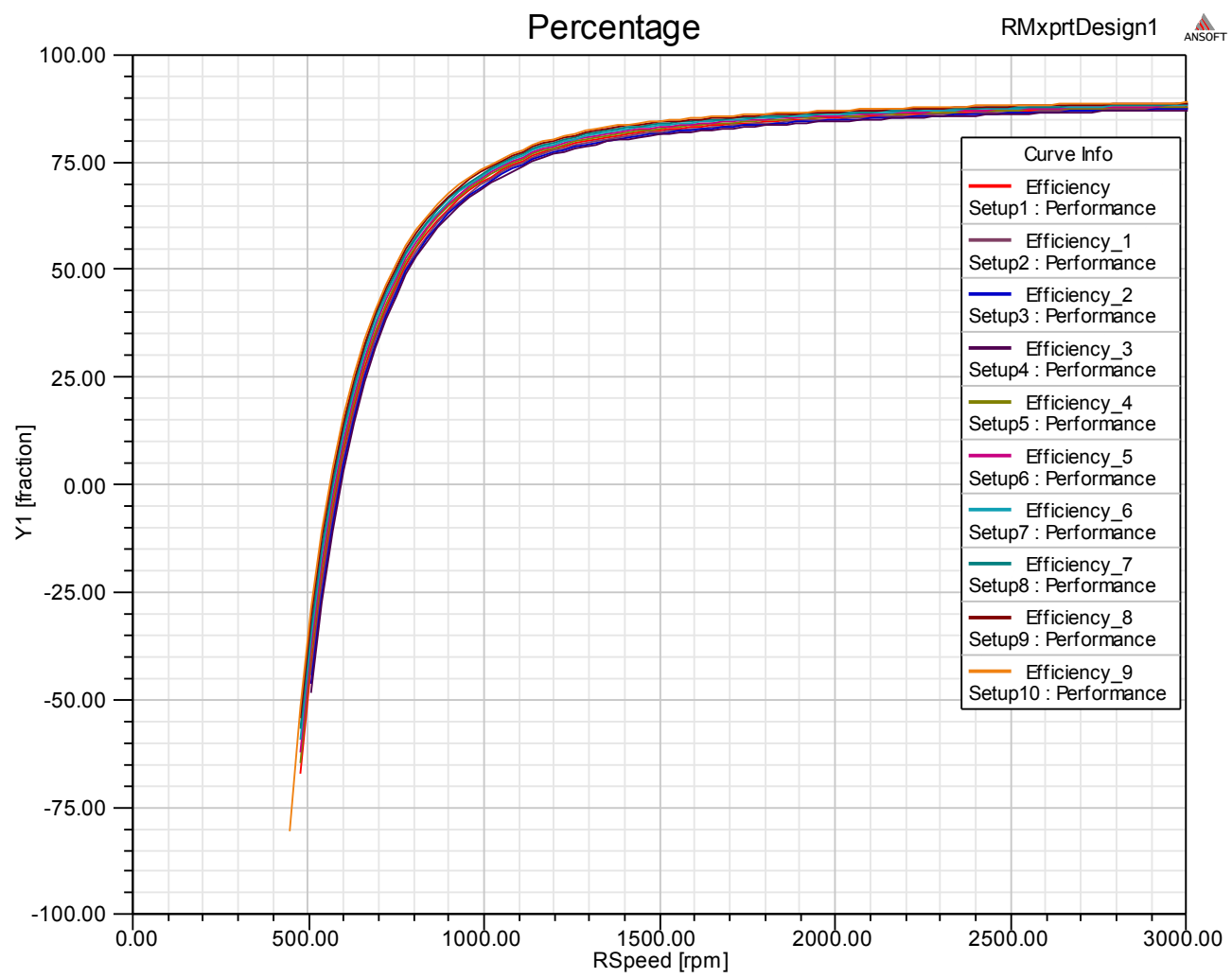

(a) Efficiency variation at different thermal condition. 


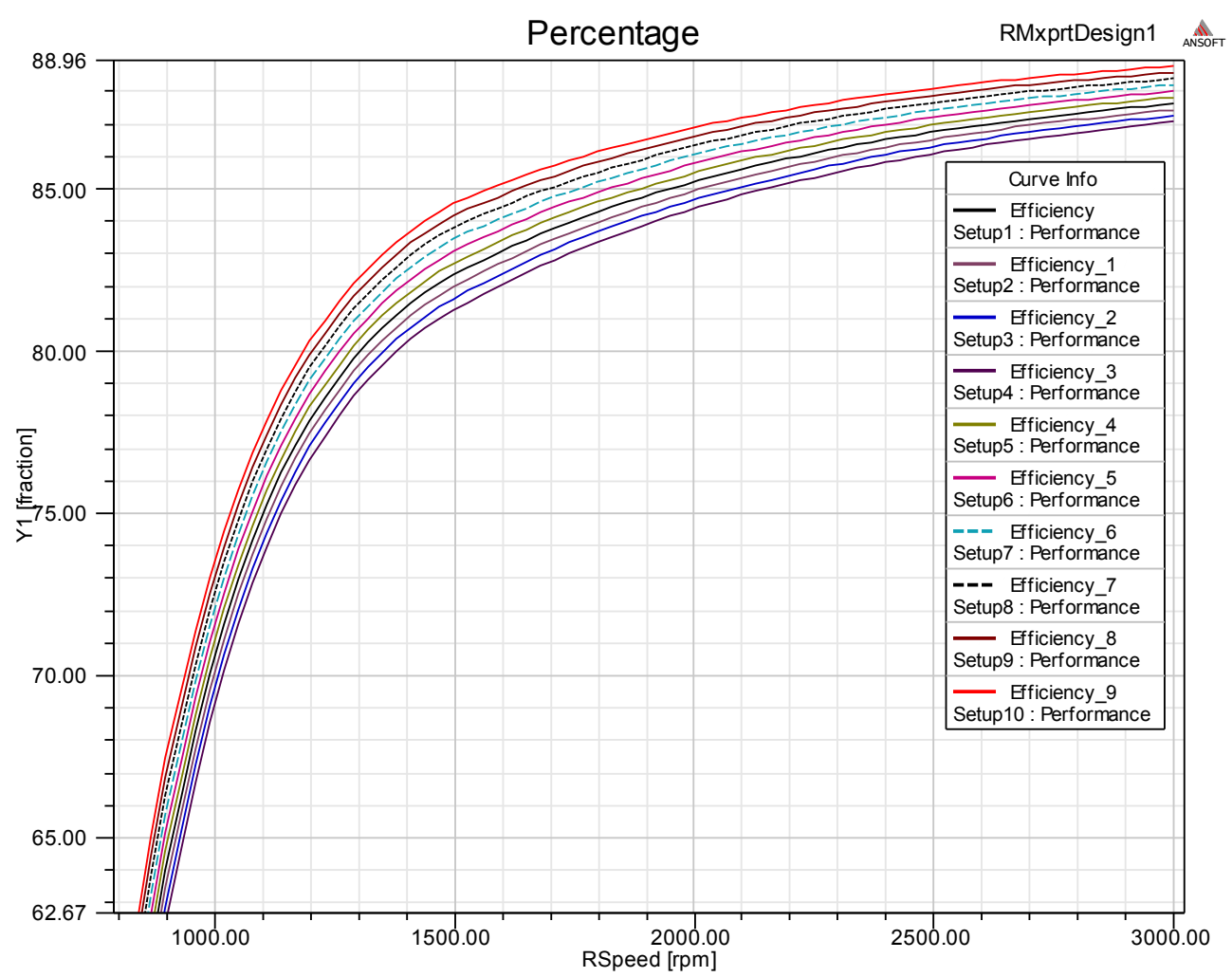

(b) ZOOM

Figure 7. Efficiency variation at different thermal condition.

\subsection{Dynamic Curve}

Fig. 8 show the torque variation, the torque value in steady state is $-3.75 \mathrm{Nm}$.

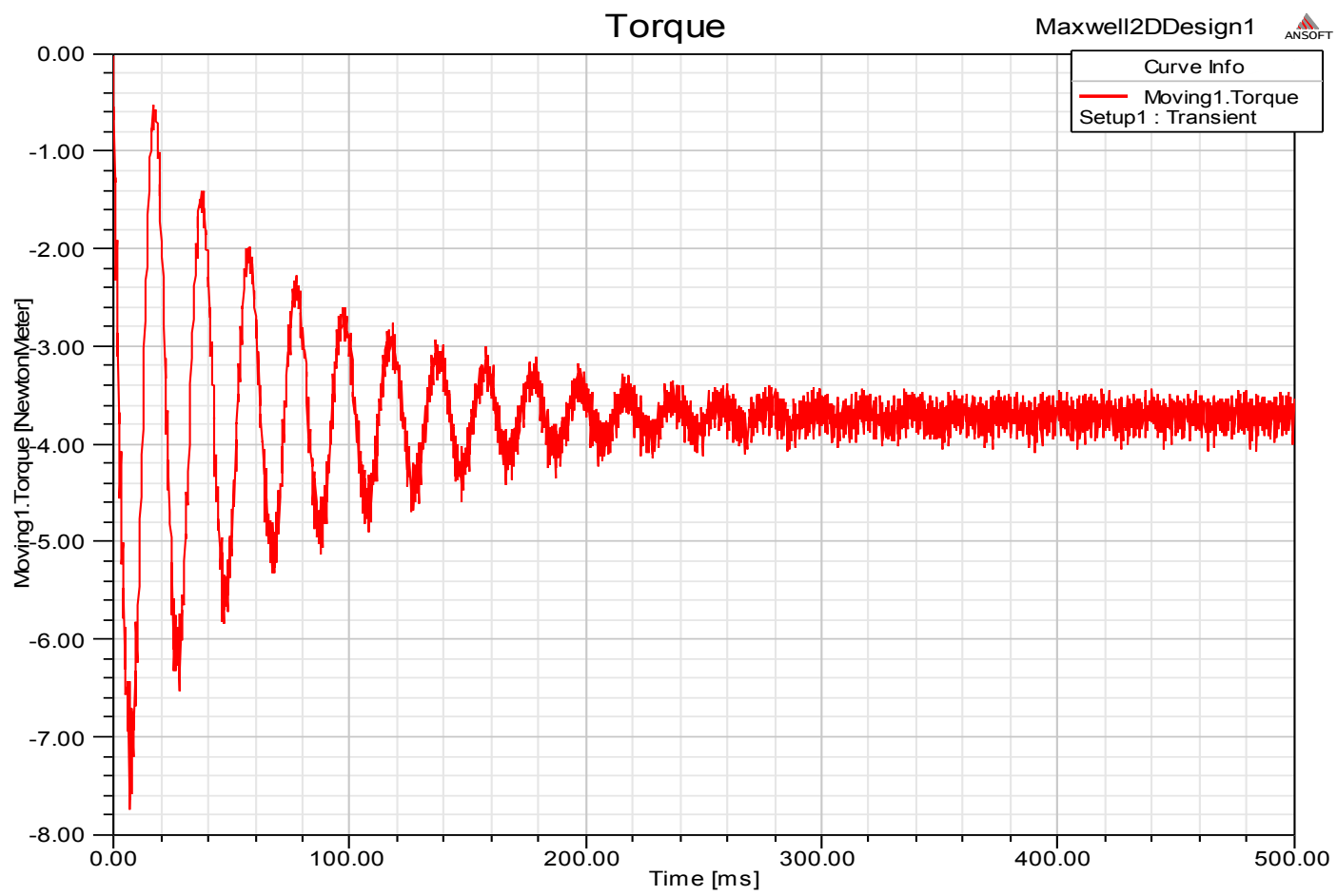

Figure 8. Torque in DFIG outer rotors.
The DFIG stator current winding is shown in Fig. 9, the magnitude is $2 \mathrm{~A}$ and the frequency is $50 \mathrm{~Hz}$. 


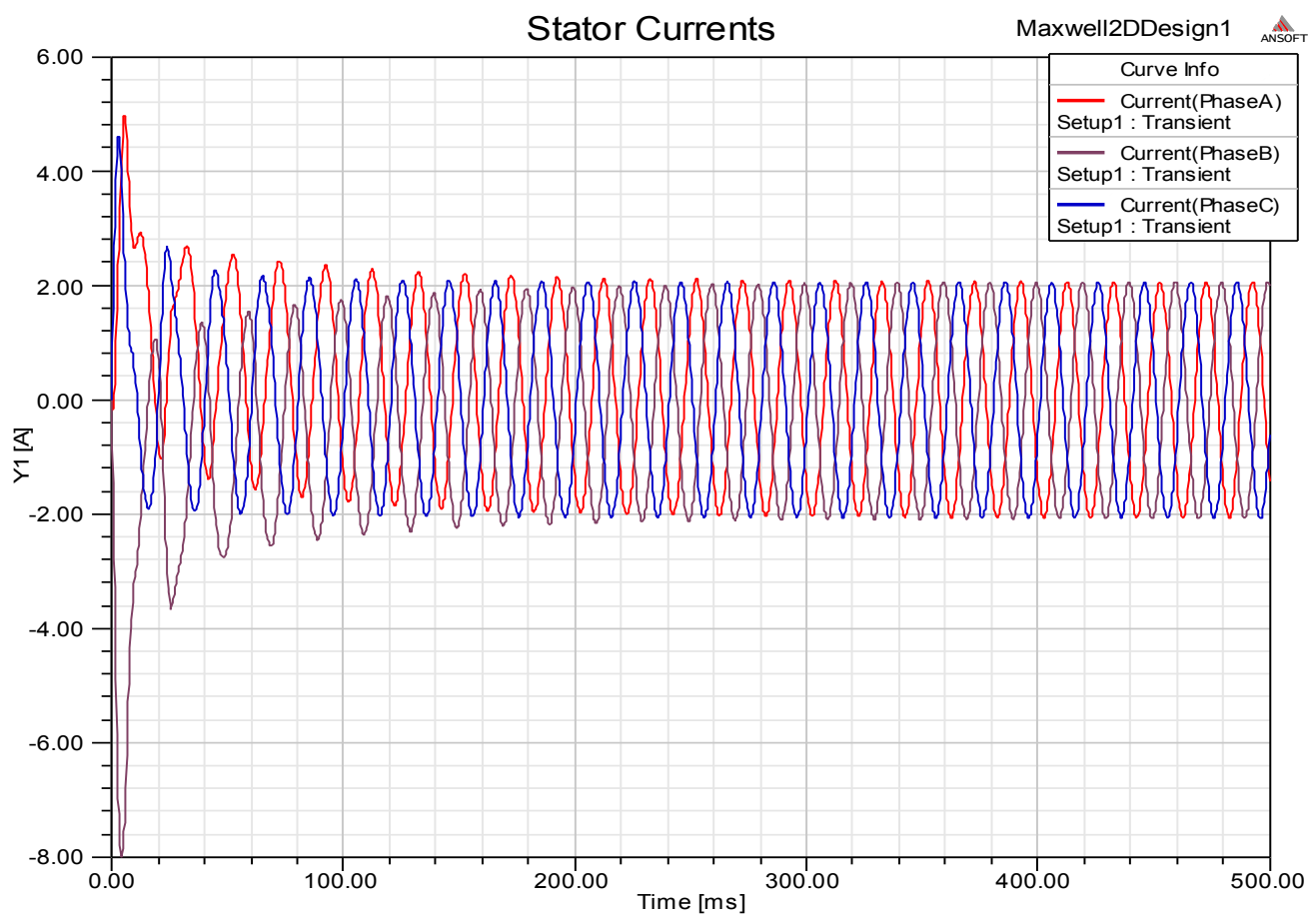

Figure 9. DFIG stator current winding.

There are two types of stranded loss quantities, Stranded Loss and Stranded LossR [15], [19]:

- Stranded Loss represents the resistive loss in a $2 \mathrm{D}$ or $3 \mathrm{D}$ volume and is calculated by:

$$
\text { Solid Loss }=\frac{1}{\sigma} \int_{\text {vol }} J^{2}
$$

-Stranded LossR represents the loss based on $\mathrm{I}^{2}$ times the resistance $\mathrm{R}$.

Fig. 10 illustrates the two types of loss, when the value of Stranded Loss in transient state is $355 \mathrm{w}$ and stabilized at $25 \mathrm{w}$ in steady-state, but the Stranded LossR is constant at $14.3 \mathrm{w}$.

Where $\mathrm{J}$ is the conductivity of the material.

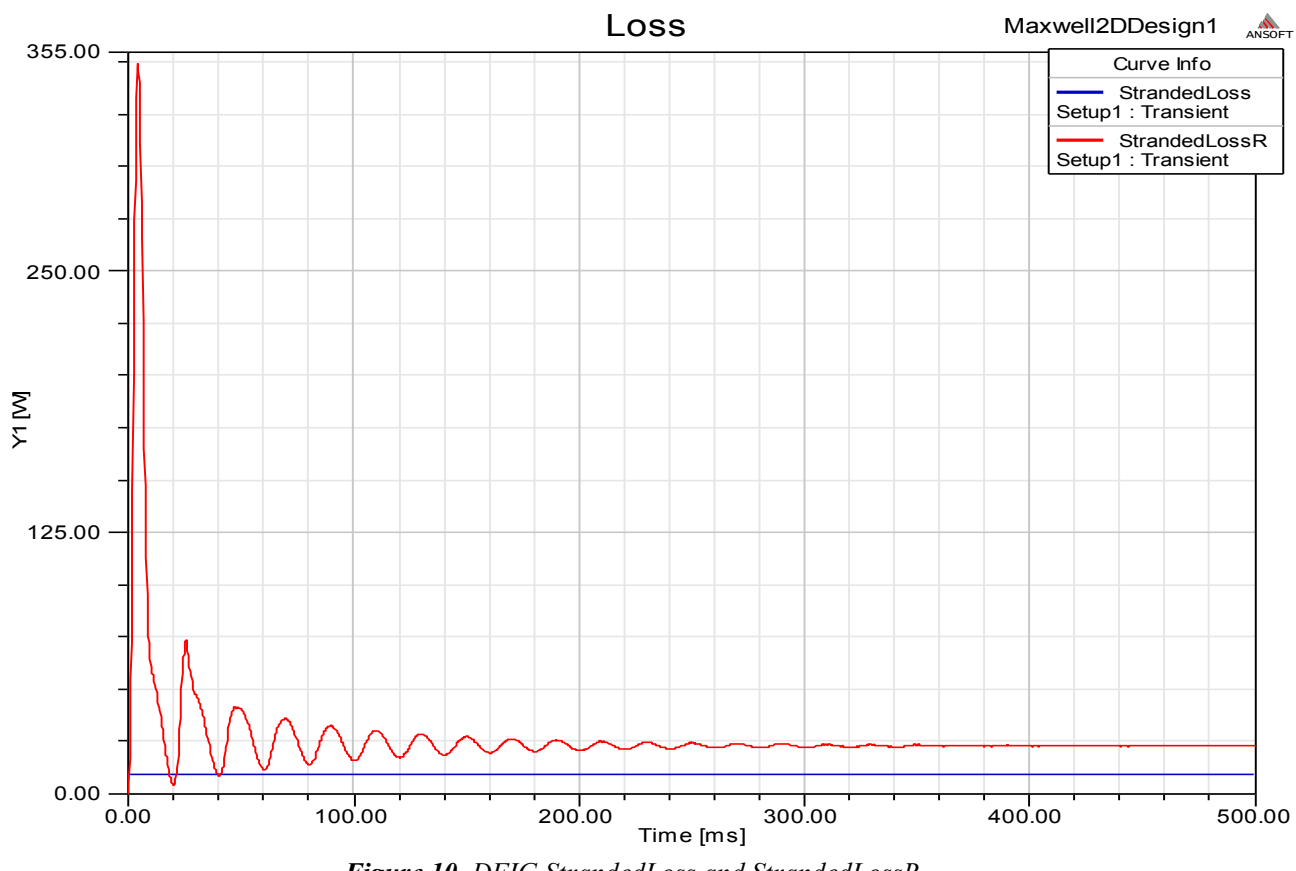

Figure 10. DFIG StrandedLoss and StrandedLossR.

Fig. 11 shows the DFIG stator and rotor induced voltage, when the value of stator is $185 \mathrm{v}$, but the value of rotor induced voltage is $25 \mathrm{v}$.

Fig. 12 shows the rotor current and stator voltage of 
DFIG, the magnitude and the frequency of the first one is respectively.

$7.12 \mathrm{~A}$ is $\approx 5 \mathrm{~Hz}$, and the second one is $180 \mathrm{v}$ is $50 \mathrm{~Hz}$

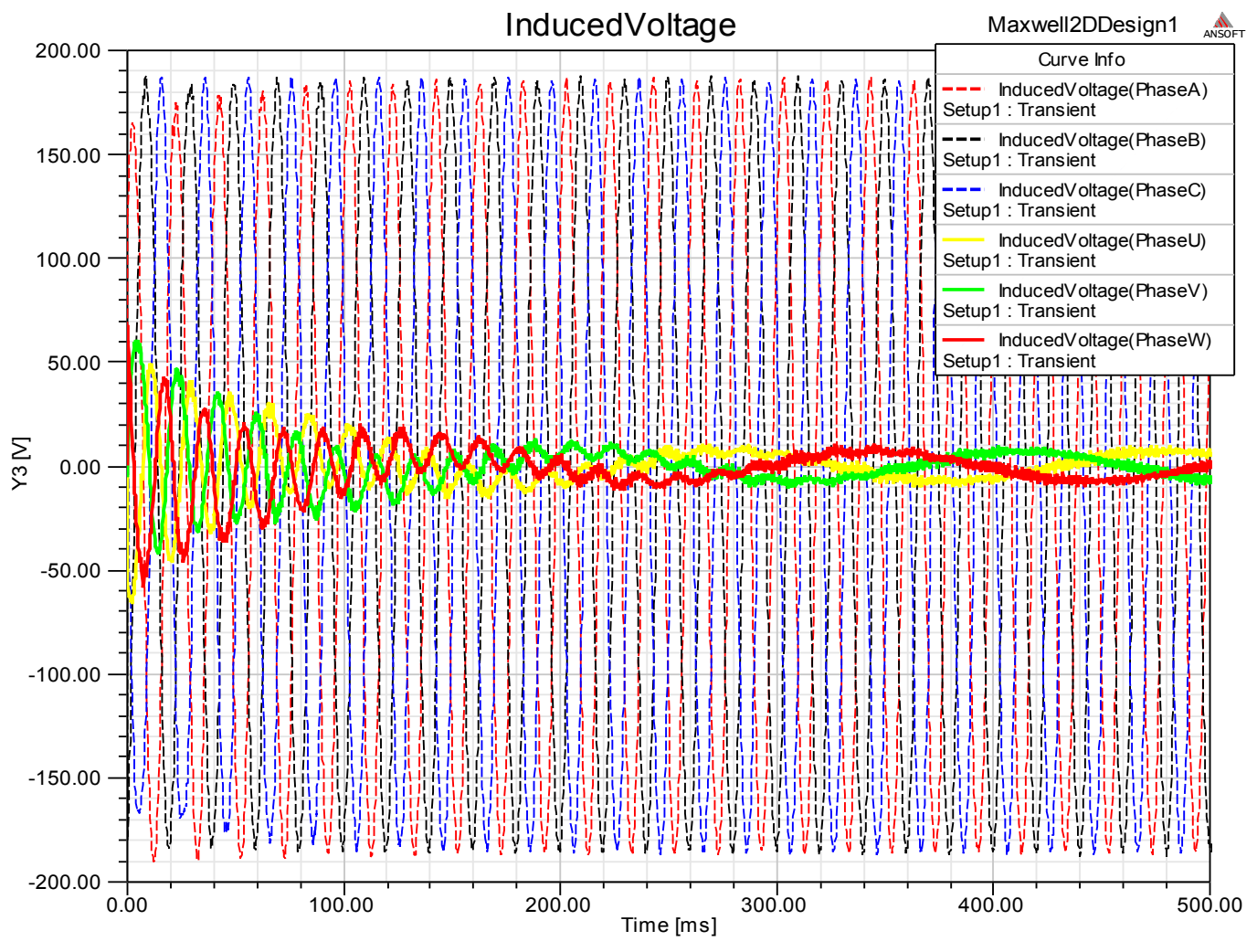

Figure 11. DFIG stator and rotor induced voltage.

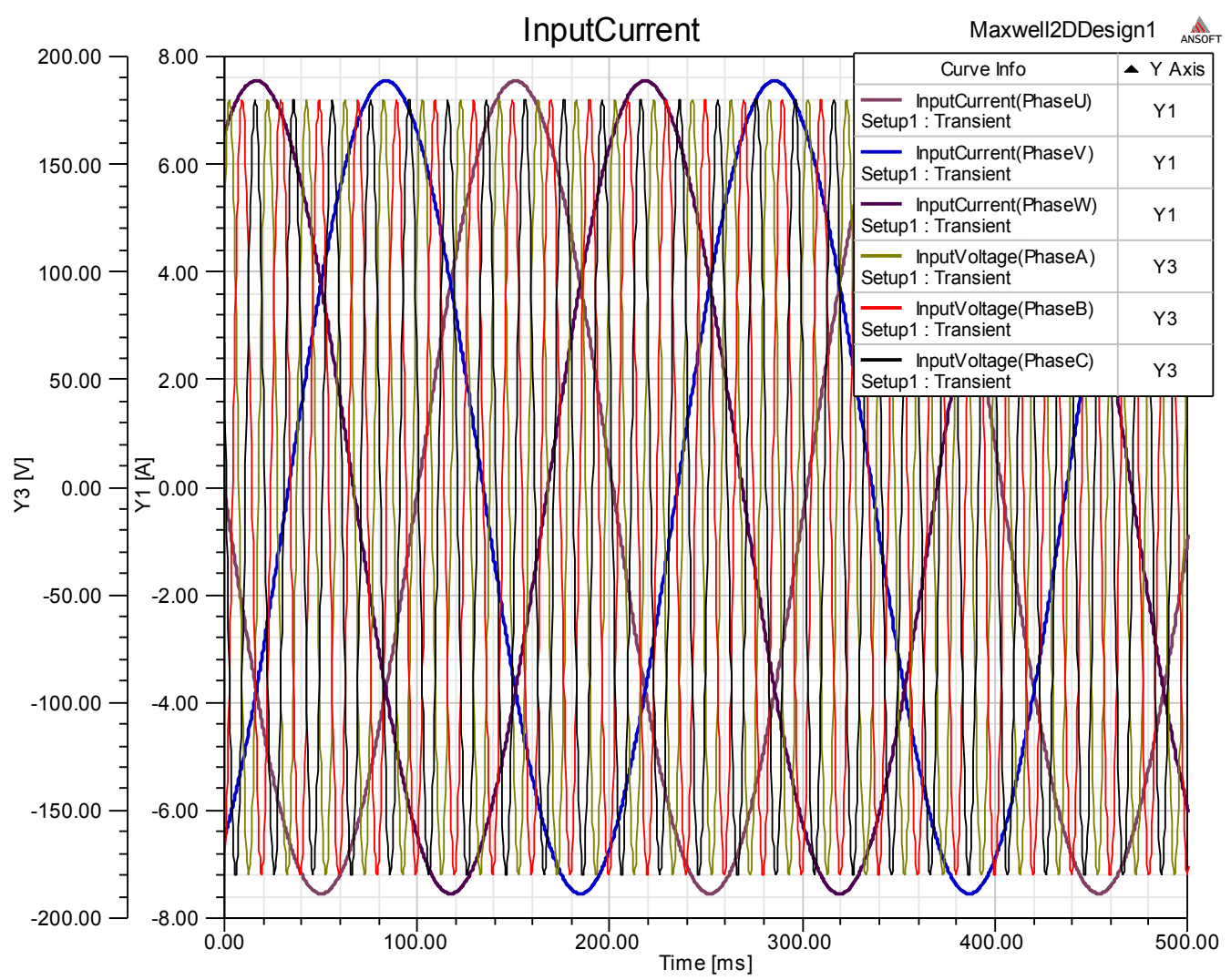

Figure 12. Rotor current and stator voltage of DFIG. 


\subsection{Field Results in $2 D$ of the Element Finite Model}

The FEA model of electromagnetic field is built by Maxwe112D, This simulation is obtained by Terra pc (QuadroFX380, i7CPU, 3.07GHZ, 8CPU, 4 G RAM), and the simulation time is $30 \mathrm{~h}$. Our model of DFIG external rotor used in Maxwell environment has 12154 triangles.

The flux, flux density, magnet field intensity are computed. The Fig.13 shows the Flux distribution and
Fig. 14 is flux line and contours diagram of flux density.

It is important to note that in order to obtain accurate results, the triangular mesh elements assigned to the airgap should have an aspect ratio close to one. A large aspect ratio between the sides of a triangular element will result in accurate computation of the flux density and hence the electromagnetic torque.

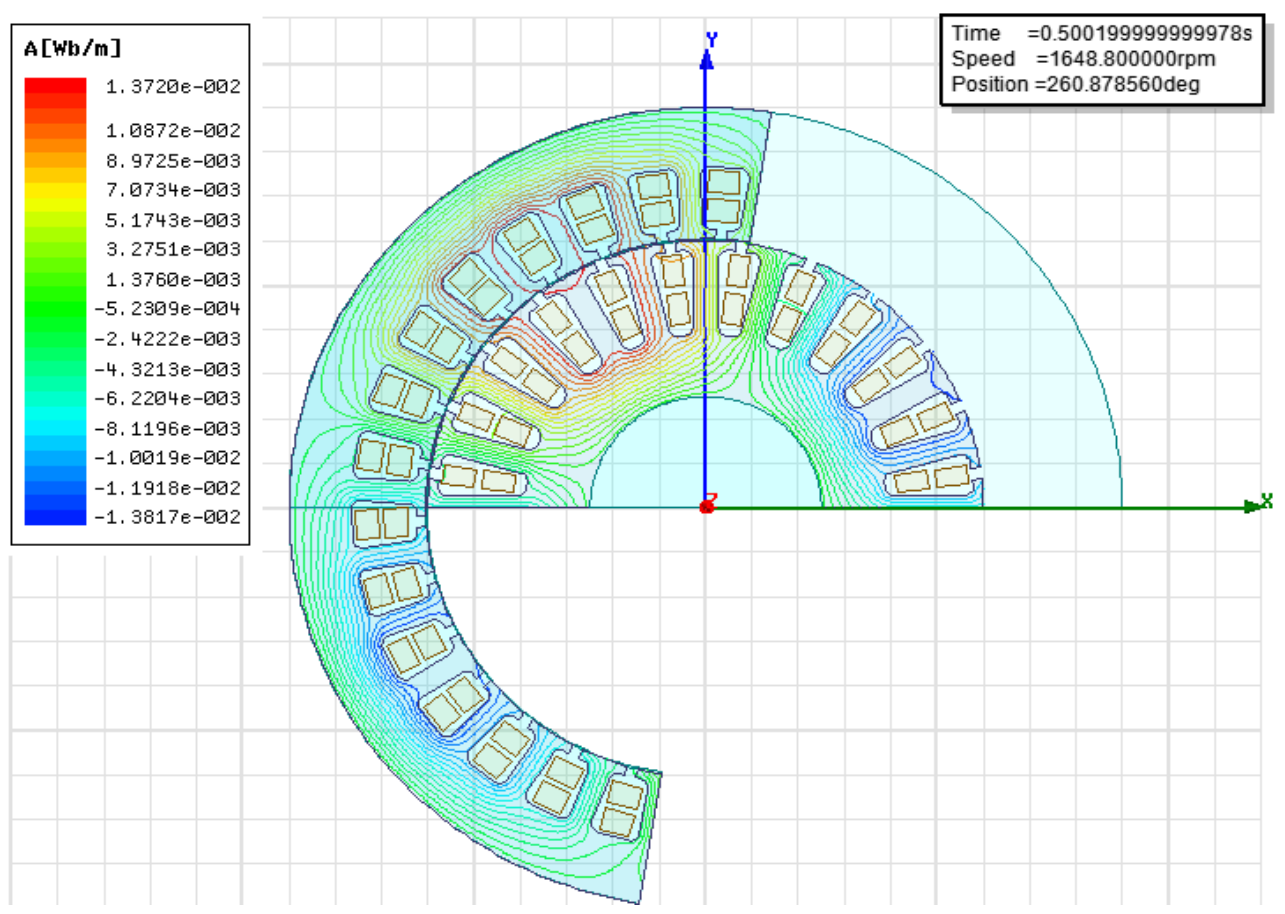

Figure 13. Flux distribution of DFIG external rotor at $0.5 \mathrm{~s}$.

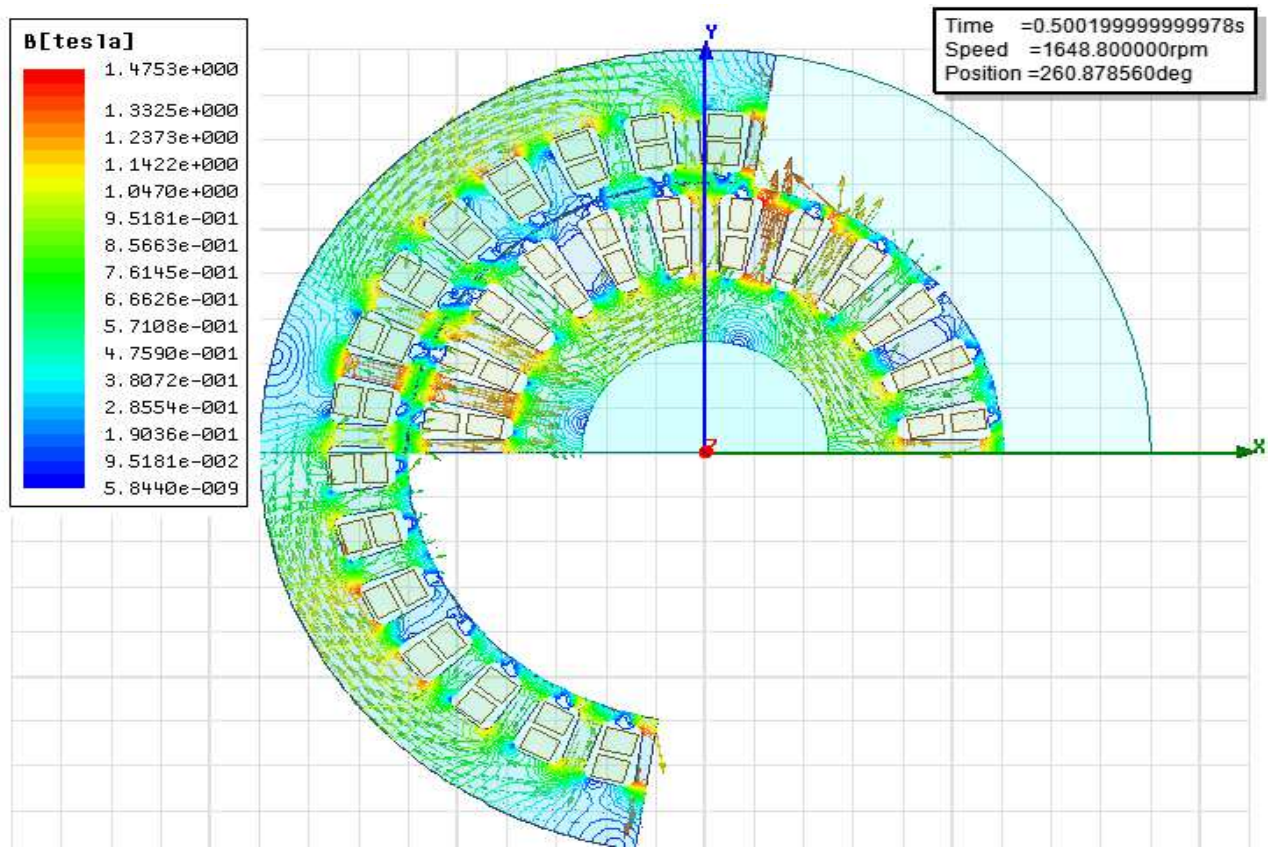

Figure 14. Contours and vector diagrams of flux density in DFIG. 
Fig.15 illustrates the total losses of DFIG; it shows that the majority of the dead losses localized in the reel are of

stator or the rotor.

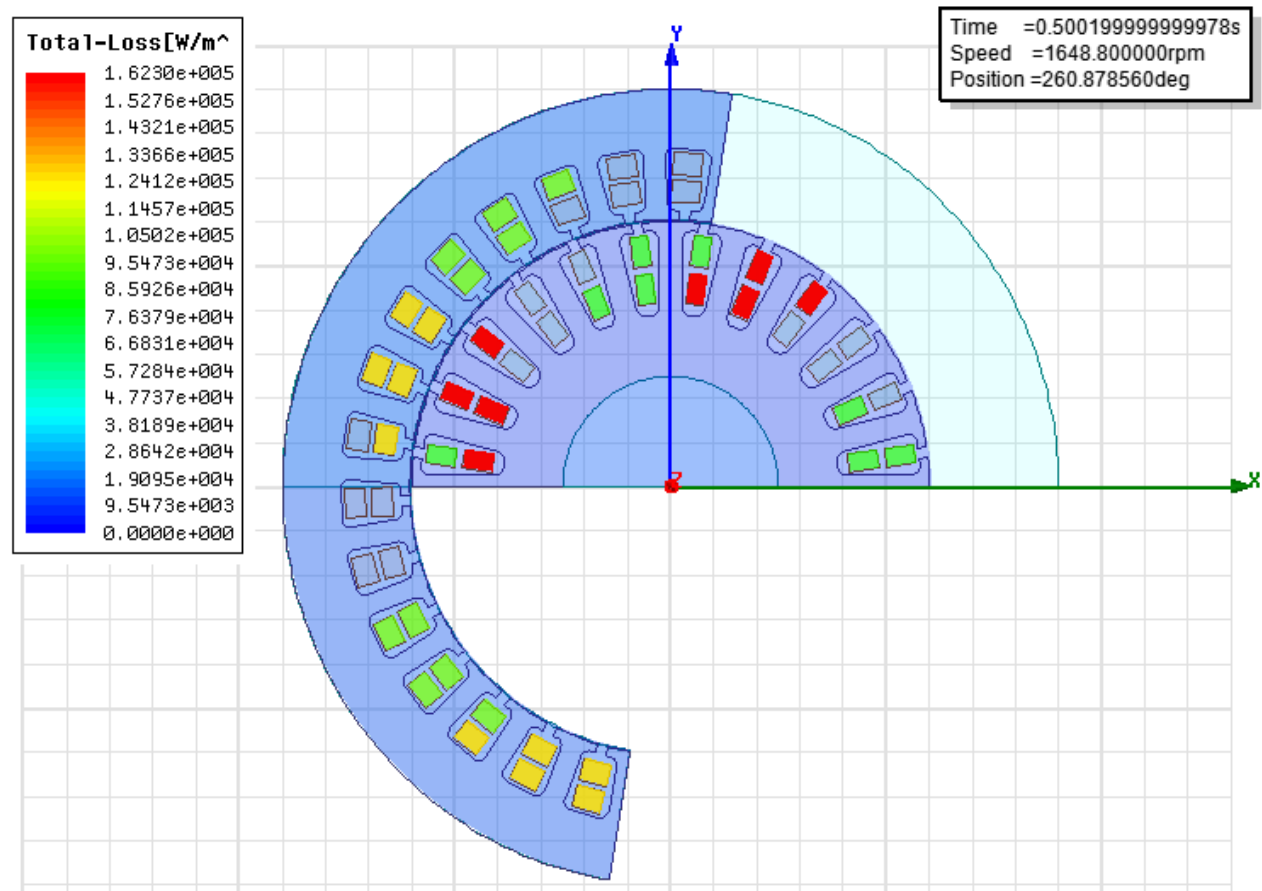

Figure 15. Total Loss of DFIG external rotor.

\section{Conclusion}

Finite element analysis (FEA) is a frequently used method for analysis of electromechanical converters. As a numerical analysis method, FEA allows for including any practical material, external excitation (voltage driven or current driven), inclusion of motion, and nonlinear effects such as magnetic saturation and eddy current effects.

A 2D model of the DFIG external rotor is given, solved, some simulation result is given and commented, to return our simulation results finer a $3 \mathrm{D}$ model is developed and solved, but the resolution time is very large, this time is a scale of the day. This work is the necessary preparations for design and development high reliability and high security of DFIG applications.

\section{References}

[1] AL. Olimpo, J. Nick, E. Janaka, C. Phill and H Mike, "Wind Energy Generation Modelling and Control", John Wiley \& Sons, Ltd 2009.

[2] I. woofenden, "wind power for dummies", Wiley Publishing, 2009.

[3] A. Petersson, Analysis, "Modeling and Control of Doubly-Fed Induction Generators for Wind Turbines", $\mathrm{PhD}$ thesis, Chalmers university of technology, GÖteborg, Sweden 2005.
[4] Martin O. L. Hansen, "Aerodynamics of Wind Turbines", Earth scan in the UK and USA in 2008.

[5] Z. Fang, "Permanent magnet machine topologies for wind power generation", university of Sheffield 2010.

[6] B.C. Pal F. Mei, "Modelling adequacy of the doubly fed induction generator for small-signal stability studies in power systems", IET Renewable Power Generation, vol. 2, Issue: 3, pp. 181-190, 2008.

[7] H. Li, Z. Chen, "Overview of different wind generator systems and their comparisons", IET, Renewable Power Generation, vol. 2, pp. 123-138, 2008.

[8] J. Krotsch, B. Piepenbreier, "Radial Forces in External Rotor Permanent Magnet Synchronous Motors With Non-Overlapping Windings", IEEE Transactions on Industrial Electronics, vol. 59, pp. 2267-2276, May 2012.

[9] P. sergeant, F. de belie, J. melkebeek, "Rotor geometry design of an interior permanent-magnet synchronous machine for more accurate sensorless control", electrical machines (ICEM), xix international conference on, pp.1-6, 6-8 Sept. 2010.

[10] İ. Tarımer, C. Ocak, "Performance Comparison of Internal and External Rotor Structured Wind Generators Mounted from Same Permanent Magnets on Same Geometry", Electronics and Electrical Engineering, vol.8, Issue. 90, pp. 67-72, 2009.

[11] S. Seman, "Transient Performance Analysis of Wind-Power Induction Generators", Doctoral theses, Helsinki University of Technology, 2006. 
[12] Z. Huiqing, C. Shiyuan, "Finite Element Analysis on Small External Rotor Brushless DC Motor", China National Knowledge, Micromotors, 2012.

[13] H. Torkaman, E. Afjei, A. Gorgani, N. Faraji, H. Karim, N. Arbab, "External rotor SRM with high torque per volume: design, analysis, and experiments", Springer-Verlag , Electrical Engineering, November 2012.

[14] D. Xiaotian, Z. Xinyan1, Z. Jun, W. Houjun, HE. Shan, "Finite Element Based Electromagnetic Field Simulation and Analysis of Doubly Fed Induction Generator", China National Knowledge, Power System Technology, 2012.

[15] H. Mellah, K.E. Hemsas, "Design and simulation analysis of outer stator inner rotor DFIG by $2 \mathrm{~d}$ and $3 \mathrm{~d}$ finite element methods", International Journal of Electrical Engineering and Technology, vol. 3, Issue. 2, pp. 457-470, July-Sept 2012.
[16] K.T.Chau, Y.B. Li, J.Z.Jiang, C. Liu, "Design and Analysis of a Stator-Doubly-Fed Doubly-Salient Permanent-Magnet Machine for Automotive Engines", IEEE Transactions on Magnetics, vol. 42, Issue. 10, pp 3470 - 3472, 2006.

[17] E. Moe, Vested interests, "Energy Efficiency and Renewables In Japan", Elsevier ,Energy Policy, vol. 40, pp 260-273, January 2012.

[18] H. Li1, Z. Chen, H. Polinder, "research report on models for numerical evaluation of variable speed different wind generator systems", Integrating and strengthening the European Research Area, 2002-2006.

[19] H. Mellah, K.E Hemsas, "Dynamic design and simulation analysis of permanent magnet motor in different scenario of fed alimentation", conference international on automatique and mécatronique, USTO, Oran, November 22-23, Algeria 2011. 